Acta Hispanica (2020) Supplementum II: 447-455

\title{
DERECHOS HUMANOS DE COMUNIDADES INDÍGENAS. COLOMBIA, LÍDER EN DESARROLLOS JURISPRUDENCIALES
}

\author{
Diana Lago - NAdia MEjÍA \\ Universidad de Cartagena
}

\begin{abstract}
Resumen: Desde la Constitución Política colombiana fundamentada en tratados y convenios de Derechos Humanos, se prevén garantías de igualdad formal ante la ley, y equidad a modo de inclusión o igualdad real, para hacer igual a los iguales y desiguales a los desiguales. Contamos, con acciones afirmativas además de sistemas de tratamiento diferencial para comunidades vulnerables que obligan tanto al ejecutivo, como al legislador, y por supuesto a los jueces, a fijar ayudas y compensaciones para sujetos que tradicional y sistemáticamente han sido amenazados o vulnerados en sus derechos. Analizamos críticamente el concepto de vulnerabilidad especialmente de comunidades indígenas, que son objeto de especial protección constitucional, y desarrollo integral entre derecho y contexto con origen en declaraciones de "Estados de Cosas Inconstitucionales", para que el mandato evolucione hacia la política, y la decisión judicial hacia el contexto reconociendo la prevalencia de la dignidad humana. Integremos vulnerabilidad con solidaridad y su contracara la igualdad ante la ley, en "sentencias estructurales", que ordenan efectivizar garantías. Indagamos por conceptos de Estado moderno, y Estado unitario descentralizado por territorios étnicos que privilegian el autogobierno con agendas de reconocimiento y reparación integral.
\end{abstract}

Palabras claves: comunidades indígenas, vulnerabilidad, derechos humanos, sentencias estructurales.

\begin{abstract}
From the Colombian Political Constitution based on human rights treaties and conventions, guarantees of formal equality before the law, and equity by way of inclusion or real equality, are provided to make the same and unequal equal to unequal ones. We have affirmative actions in addition to differential treatment systems for vulnerable communities that oblige both the executive and the legislator, and of course the judges, to establish aid and compensation for subjects who have traditionally and systematically been threatened or violated in their Rights. We critically analyze the concept of vulnerability especially of indigenous communities, which are the object of special Constitutional protection, and integral development between law and context, originating in declarations of "States of Unconstitutional Things", so that the mandate evolves towards politics, and the decision judicial towards the context recognizing the prevalence of human dignity. We will integrate vulnerability with solidarity and its counterbalance to equality before the law, in "structural sentences", which order to guarantee guarantees. We inquire about concepts of modern state, and unitary state decentralized by ethnic territories that privilege selfgovernment with agendas of recognition and integral reparation.
\end{abstract}

Keywords: Indigenous Communities, Limitations, Human Rights, Structural Sentences.

Acta Hispanica, Hungría, Supplementum II: 447-455, 2020, ISSN: 1416-7263 | 447 
Derechos humanos de comunidades indígenas. Colombia, líder en desarrollos jurisprudenciales

\section{Introducción}

La progresividad de los derechos humanos nace de convenios, tratados y normas fundantes como pilar básico y razón de ser, del actuar y las omisiones de los servidores públicos, y se mantiene como prevalencia de derechos fundantes en manifestación expresa de protección integral.

La declaración universal de Derechos de 1948, consagra ideales de igualdad entre naciones y pueblos que deben esforzarse para que individuos e instituciones, promuevan la educación y la enseñanza del respeto por derechos y libertades, asegurando reconocimiento y aplicación inmediata. "Todos los seres humanos nacen libres e iguales en dignidad y derechos y dotados como están de razón y conciencia, deben comportarse fraternalmente los unos con los otros". Toda persona tiene derechos y libertades sin distinción de raza, color, sexo, idioma, religión, opinión política, origen nacional o social, posición económica, nacimiento o cualquiera otra condición.

No obstante estas declaraciones, la vulnerabilidad se ha abierto paso como manifestación de amenaza o daño a los derechos en estados que omiten o se extralimitan, suscitando declaraciones judiciales de "estados de cosas inconstitucionales", y sentencias estructurales que confrontan el manejo de lo público, con garantías para lo fundamental. Estas sentencias compelen a la creación de normas, políticas de compensación y reparación, veedurías y mecanismos de participación de la sociedad civil como un todo, en defensa de los derechos.

Respecto de grupo marginado y discriminado, la Corte Constitucional, mediante sentencia C- 741 de 2003, señalaba que el primero, es un término amplio que comprende a los que por sus condiciones de vida, se encuentran en situación de exclusión social, no han podido incorporarse a actividades económicas y tienen imposibilidad de acceder a los beneficios de una sociedad organizada; el segundo en cambio, es un acto abierto o soterrado de vulnerabilidad en razón de las diferencias, o de especiales condiciones de vida de las que no se puede prescindir, sin perder la esencia.

La vulnerabilidad social, según la Corte, se relaciona con circunstancias que impiden a individuos y grupos, procurarse su subsistencia, niveles altos de bienestar debido a riesgos a los que están expuestos y situaciones de desprotección o desventaja. Las situaciones que ponen a una persona en condición de vulnerabilidad está la precariedad laboral la ausencia o mala remuneración, inexistencia de contrato, no afiliación a sistemas de seguridad social e inestabilidad laboral, discriminación y violencia. En sentencias T230 de 1994, y C-309 de 1997, la Corte afirma que los casos que limitan el goce de derechos a grupos de personas, hacen que el escrutinio a la decisión judicial es más intenso, "la Carta indica que todas las personas tienen derecho a igual protección de sus derechos y libertades". El Juez constitucional observa con especial cuidado, que se trata de situaciones que afectan a comunidades en Estado de debilidad manifiesta. 
En sentencia T-736 de 2015, la Corte afirma que una comunidad es discriminada o marginada, o se encuentra en estado de vulnerabilidad cuando: i - es un grupo social plenamente identificado o identificable; ii - se encuentra en situación de subordinación e indefensión prolongada; iii - su poder político está severamente limitado respecto de los demás, y, iv - padece condiciones socio económicas, de clase que la amenaza o perjudica. Son grupos tradicionalmente excluidos, explotados, estereotipados e invisibilizados y sus miembros sufren violencias o amenazas. Así, los desarrollos jurisprudenciales de sentencias estructurales en favor de pueblos indígenas integran dignidad, igualdad y derecho identitario, imponiendo al Estado obligaciones de garantía y compensación.

\section{Comunidad indígena, vulnerabilidad y derechos}

En este aparte, miramos dimensiones conceptuales de los encargados de la protección integral, en consonancia con declaraciones de Derechos Humanos en favor de comunidades indígenas, en condición de "vulnerabilidad manifiesta", lo que acredita "estados de cosas inconstitucionales", que reclaman sentencias estructurales, sin desdeñar de la división de poderes.

La Corte Constitucional mediante sentencia T-244 de 2012, llama vulnerabilidad al proceso multidimensional en el que confluyen riesgos o probabilidades de individuos de ser heridos o lesionados por cambios o permanencias y situaciones externas o internas. Identificar situaciones de vulnerabilidad, demanda indagar primero, por circunstancias que exponen a los sujetos a desbalances, segundo, por características y atributos de los sujetos vulnerables, tercero, la no dependencia de lo meramente formal, cuarto, que se trate de derechos subjetivos, acciones y etapas para la protección integral de derechos. Un análisis crítico de contextos y situaciones en las que se encuentran los sujetos, imponen al Estado y luego al juez, obligaciones de verificar posibles afectaciones antes de ordenar la implementación de leyes y políticas públicas de impacto, evitar el escalamiento de la indefensión, la exclusión y la comisión de delitos y arbitrariedades.

Mediante sentencia T-670 de 2017, la Corte Constitucional reconoce vulnerabilidad cuando se acreditan las siguientes condiciones: $\mathrm{i}$ - pertenecer a un grupo de especial protección constitucional, ii - hallarse en una situación de riesgo o amenaza y iii - carecer de resiliencia, o capacidad para resolver las propias necesidades. La declaratoria de “estado de vulnerabilidad", debe, i - ser demostrada por el sujeto que la alega; ii - acreditar que su presunto estado se debe a la pertenencia a un grupo de especial protección constitucional, según mandato del artículo 13 constitucional; iii - ser el Estado, destinatario del reclamo o la demanda por derechos; iv - estar obligado el Estado, a proteger a individuos en situación de debilidad manifiesta, y a promover y hacer posible la igualdad real y efectiva.

En el Caso Rosendo Cantú contra México, la Corte Interamericana de Derechos Humanos, dijo que una población indígena es vulnerable, desde diferentes ámbitos: administración de justicia, servicios de salud, no hablar español ni contar con intérpretes, 
Derechos humanos de comunidades indígenas. Colombia, líder en desarrollos jurisprudenciales

falta de recursos económicos para acceder a abogados, tenerse que trasladar a centros de prestación de servicios, y ser víctima de prácticas abusivas o violatorias del debido proceso. Para la Corte Constitucional, la vulnerabilidad se enmarca en la omisión de deber de las autoridades de luchar por la erradicación de las desigualdades sociales; los riesgos surgen de la permanencia de situaciones que impiden la efectividad de la autonomía y el derecho a subsistir, la amenaza de verse sumergido en situaciones de incapacidad, de procurarse el mantenimiento mínimo, o alcanzar niveles más altos de bienestar.

Demandas y reclamos de comunidades indígenas por acciones afirmativas o discriminación a la inversa, son aplicables a grupos históricamente discriminados por sus costumbres y cosmogonías a modo de derechos comunitarios, que por encontrar limitaciones, buscan reconocimiento y restitución de sus derechos humanos.

Aunque el marco jurídico colombiano no tiene definiciones únicas y definitivas sobre vulnerabilidad, la misma Constitución Política consagra derechos de igualdad ante la ley, e igualdad real y efectiva para poblaciones en condición de discriminación, desigualdad o vulnerabilidad, y la Corte Constitucional como garante, concede a estos grupos, la calidad de ser sujetos de especial protección constitucional, declarando que existen "estados de cosas inconstitucionales". Así, estas poblaciones encuentran su legitimidad para el reclamo de sus derechos, esencialmente en su condición de encontrarse en dicho estado, que los convierte en sujetos de especial protección.

Mediante sentencia T-386 de 2013, la Corte Constitucional señala que el Estado Colombiano, en desarrollo de su deber ser como autoridad suprema, debe luchar por la erradicación de las desigualdades sociales y está obligado a diseñar agendas y ejecutar políticas públicas para lograr igualdad real y efectiva para comunidades vulnerables. Lo anterior significa, implementación de medidas no regresivas, ni agravantes de su marginalidad y entonces cuando actuaciones políticas, planes o programas generen afectaciones a estas comunidades, debe asegurarse que, "estén sometidas a parámetros de razonabilidad y proporcionalidad y acompañadas de medidas que contrarresten los impactos negativos."

Mediante sentencia T-736 de 2015, la Corte Constitucional, señala: "la igualdad es fundamental para la concreción del Estado Social de Derecho y debe guiar el carácter y objetivo de la organización estatal". La igualdad tiene dos dimensiones, una formal, como igualdad ante la ley, y prohibición de discriminar bajo criterios sospechosos; dos material, y ordena la adopción de acciones positivas de promoción a favor de grupos históricamente discriminados para lograr igualdad real y efectiva. Desde allí, la Corte ordena protección especial para personas en situación de debilidad manifiesta "por su condición económica, física, o mental".

El concepto de comunidades mecánicamente diferenciadas es de mayor complejidad, porque supone de un lado protección de derechos, y del otro, especial cuidado con formas de vida, imaginarios y creencias que las comunidades tienen, evitando posibles procesos de aculturación. En todo caso, ha sido la Corte Constitucional la encargada de velar por la reivindicación de derechos de comunidades vulnerables, mediante las 
llamadas sentencias estructurales que obligan al Estado a integrar leyes, políticas públicas y agendas inclusivas de promoción y protección de Derechos Humanos en beneficio de las comunidades. Desde las construcciones jurídicas de las altas Cortes, se implementan estrategias de equidad con miras a lograr la inclusión de grupos étnicamente diferenciados, ubicados en los espectros de protección especial de las comunidades vulnerables.

Leyes y normas, política pública y nuevas instituciones de acuerdo con competencias específicas, imprimen atención integral a grupos con vulnerabilidad manifiesta que gozan de las siguientes características, según la sentencia T-736 de 2015, de la Corte Constitucional: $\mathrm{i}$ - ser una grupo con rasgos comunes y socialmente identificables; ii encontrarse en situación de subordinación prolongada; iii - el poder político está severamente limitado por condiciones socio económicas, de clase, o perjuicios ajenos; iv - ser grupos explotados, estereotipados e invisibilizados, en los que sus miembros sufren violencias por hacer parte de él.

\section{Constitución tierra y territorio indígena}

En este aparte analizaremos conceptos de identidad, cultura y territorio de estirpe constitucional generados en razón de tratados, convenios y normas fundamentales, retomados por la Corte Constitucional para favorecer a las comunidades indígenas, en su reconocimiento, reparación y compensación sin que pueda endilgárseles activismos judiciales o litigios estratégicos, en razón de ser las obligadas a mantener la supremacía de la Constitución y los bloques de constitucionalidad.

Los pueblos indígenas tradicionalmente han construido su cosmovisión y su cultura desde sus territorios por ser estos, los espacios de convivencia y trabajo común, que les permite transmitir valores en conexión con imaginarios de un mejor vivir. Para Skliar Carlos los indígenas tienen su propia percepción de la vida, del mundo con los otros y de las cosas que los conmueven como exterioridad de sí mismo, de comunicación, de lenguajes y tradiciones que los convocan con el pasado ancestral y las prerrogativas de futuro (2014: 95).

La garantía de los derechos, deviene del respeto por el territorio, la identidad y la cosmogonía; las sentencias de la Corte Constitucional, tienen como pilar la protección integral y el reconocimiento de derechos objeto de estudio desde los inicios de la Constitución de 1991, la ley 21 de 1991, y normas que protegen la diversidad étnica y cultural de la nación, imaginarios de identidad, espacios físicos y recursos naturales con sostenibilidad.

Sentencias estructurales reconocen derechos sobre la tierra y sus recursos, además de derechos de libertad y autonomía para decidir sus prioridades y derechos de autorregulación. Mediante sentencia T-188 de 1993, la Corte Constitucional destaca la especial relación de los pueblos aborígenes y las comunidades indígenas junto con el territorio que ocupan, no solo porque es su principal medio de subsistencia, sino porque 
Derechos humanos de comunidades indígenas. Colombia, líder en desarrollos jurisprudenciales

constituye elemento integrante de su religiosidad. En sentencia T-380 de 1993, reafirma que el reconocimiento del derecho a la propiedad colectiva de los resguardos, consagrado en la Constitución Política artículo 329, comprende la propiedad colectiva sobre los recursos naturales no renovables existentes en sus territorios.

Para la Corte Constitucional, los territorios indígenas no están determinados por el reconocimiento de títulos de dominio, por el contrario, los pueblos que los habitan, están intrínsecamente ligados a una noción de ancestralidad, pues es primordialmente una forma de desarrollar creencias, encontrar formas de subsistencia y en fin, todo lo que se contrae a la especial cosmovisión de cada comunidad, no ligado al concepto occidental de propiedad, haciendo de comunidades, cultura, cosmovisión y territorio, una unidad inescindible de especial protección constitucional.

Una comunidad indígena considera el territorio, no son solo como forma de subsistencia, sino como espacio con el que mantiene una especial relación física, mental, emocional. Constituye un lugar de recreo para la tradición, los ritos sagrados y elementos integrantes de su cosmovisión e identidad. Los pueblos, derivan su existencia como grupo culturalmente diferenciado, por el territorio que ocupan. Los derechos fundamentales de un pueblo indígena a preservar la integridad de su cultura y sus costumbres, se efectiviza desde el ejercicio informado y participante para adoptar las decisiones que les competen dentro de sus propios territorios, a modo de elemento integrante de su propio Estado.

En la sentencia T-693 de 2011, la Corte afirma que la relación comunidad - territorio, no es la misma que tiene la cultura occidental, ya que, estos pueblos consideran que la tierra y el territorio están íntimamente ligados a su existencia y supervivencia desde el punto de vista religioso, político, social y económico; no constituye un objeto de dominio sino un elemento del ecosistema con el que interactúan. "La propiedad de la tierra no recae sobre en los individuos, sino en el grupo, de modo que adquiere carácter de colectiva".

En la sentencia T-739 de 2014, la Corte Constitucional finca la soberanía de las comunidades indígenas en la protección, garantía y respeto por cultura e identidad y por igualdad de los nacionales como presupuesto de avance hacia "la creación de un Estado que reconozca las diferencias y equilibre las cargas injustamente impuestas a estas comunidades". El concepto de territorio es dinámico y comprende todos los espacios imprescindibles para acceder a recursos naturales que hacen posible su reproducción material y espiritual, según características propias de su organización productiva y social.

Mediante sentencia T-849 de 2014, define la importancia que debe darse a las partes del territorio que son sagradas o tienen importancia cultural, "la protección del territorio no se limita a aquellos que se encuentran titularizados"; se trata de un concepto jurídico que se extiende a toda la zona indispensable para garantizar el pleno y libre ejercicio de actividades culturales, religiosas y económicas, de acuerdo a cómo las han venido desarrollando sus ancestros. El Estado tiene la obligación de proteger a las comunidades indígenas de perturbaciones que puedan sufrir en el ejercicio de actividades en el considerado "territorio ancestral", y debe tomar las medidas pertinentes para evitar que 
las conductas de los particulares afecten sus derechos, para ello se establece la consulta previa y el consentimiento libre e informado.

La sentencia C-389 de 2016, señala: "el territorio, es un concepto cultural, que difiere del concepto tierra como bien inmueble, sujeto a las leyes del mercado y la libre disposición de los particulares". Para las comunidades indígenas el territorio es el espacio donde se consolida la autonomía y se desarrolla la cultura; un espacio en el que la relación de los pueblos originarios con la naturaleza, se vivencia y materializa. Por todo lo anterior, el Estado Colombiano, consciente de la contribución de las comunidades étnicas a la diversidad y el pluralismo social además del respeto, cuidado y preservación de los recursos naturales, a los que tienen derecho ha decidido motu propio o por mandato de la Corte Constitucional, adoptar medidas de protección de sus territorios para impedir que sean objeto de alteraciones, sin que antes hayan dado su aprobación.

\section{Territorios étnicos y sentencias estructurales}

En este aparte, veremos desarrollos normativos en favor de las comunidades indígenas, como tratados internacionales, convenios como el 107 de la OIT, que reconoce derechos de propiedad colectiva, prohibición de traslado del territorio sin consentimiento, respeto por usos y costumbres con enfoque integracionista y el convenio 169 sobre pueblos indígenas y tribales que busca protección integral para comunidades indígenas y su autonomía personal, que nutren decisiones jurisprudenciales por existir precaria regulación de las entidades territoriales indígenas.

Respecto de la autonomía indígena la Corte Constitucional en sentencia SU-383 de 2003, señala que Colombia como Estado social de derecho democrático, participativo y pluralista, debe respetar y procurar por el reconocimiento de la diversidad de la nación colombiana, a tal punto que debe considerar la participación e identidad indígena, como presupuestos de existencia del Estado, y requisitos inescindibles para construir una nacionalidad única y real, fundada en una diversidad viable. Existe para ellos, un marco amplio de derechos así: i - los territorios, son propiedad colectiva de las comunidades étnicas; ii - las tierras de resguardos, son inalienables, imprescriptibles e inembargables y iii - los indígenas gozan de garantías de acceso a la propiedad privada.

Destacamos que la sentencia C-389 de 2016, señala los casos en que existe afectación directa, a una comunidad, así: i - se intervienen derechos de pueblos indígenas o tribales; ii - se desarrollan presupuestos del Convenio 169, OIT, iii - se imponen cargas o se atribuyen beneficios que modifican situaciones o posiciones de la comunidad; iv - se interfieren elementos definitorios de la identidad o la cultura del pueblo; $\mathrm{y}, \mathrm{v}$ - se afecta con especial intensidad o de manera diferenciada a pueblos étnicamente diferenciados.

Mediante sentencia SU-097 de 2017, la Corte dijo que cuando hay aspectos graves en sí mismos, o afectación directa, y por ende "la protección especial es aplicable", cuando: $\mathrm{i}$ - existen patrones no superados de discriminación, que afectan a pueblos y personas étnicamente diversas; ii - se ejerce presión por parte de la cultura mayoritaria a la 
Derechos humanos de comunidades indígenas. Colombia, líder en desarrollos jurisprudenciales

comunidad en razón de su cosmovisión; iii - las afectaciones del conflicto armado les generan explotaciones, despojos y usos estratégicos de tierras y territorios.

La sentencia T-739 de 2017, señala que es indispensable que "el Estado elabore políticas públicas, culturalmente específicas dentro de centros urbanos, para asegurar que los indígenas no se vean obligados a renunciar a su auto-reconocimiento como comunidad" y disfruten igualmente de progresos alcanzados en esas esferas. "Los pueblos indígenas no deben considerarse divididos entre medio urbano y medio rural sino como pueblos con derechos e identidad cultural común, en proceso de adaptación a circunstancias y entornos cambiantes."

Si se quiere delimitar el alcance de la autonomía jurisdiccional indígena se debe acudir a la conciencia étnica de los grupos involucrados en las decisiones, y al conjunto de elementos que distinguen al pueblo como perteneciente a una cultura, a fin de que el intérprete pueda determinar en qué medida y con qué alcance debe reconocer el derecho a la integridad cultural, cuando se trata de reprimir y sancionar conductas delictivas.

La Corte Constitucional mediante sentencia C-565 de 2017, la Corte Constitucional, hace obligatoria la consulta previa, en casos en que medidas legislativas o administrativas afectan directamente a la comunidad indígena. La tutela constituye mecanismo preferente y sumario para la protección de comunidades étnicas y el juez constitucional en su garante. La sentencia T-800 de 2014, había hecho énfasis, en la tutela como mecanismo de protección de los derechos de los pueblos étnicos y la razón de su utilización, toda vez, en el ordenamiento jurídico colombiano, no hay mecanismos diferentes a la tutela para la protección de sus derechos y que aun si existieran acciones judiciales ante las jurisdicciones ordinaria o administrativa, la procedibilidad de la tutela se constituye en la vía idónea para proteger la integridad cultural de estas comunidades.

Desarrollado el concepto de consulta previa para escenificar principios fundantes como reconocimiento, participación y protección de su diversidad étnica y cultural, con enfoque de garantías de prácticas, usos y costumbres, la jurisprudencia unifica mandatos, principios y derechos de autodeterminación, propiedad e identidad cultural para su protección y defensa.

\section{Conclusiones}

La omisión legislativa como inactividad del legislador, por "no hacer", no regular u omitir pronunciamientos frente a álgidos temas de reconocimiento y garantías para las comunidades étnicas que por mandato constitucional deberían serlo, ha suscitado para la Corte Constitucional la necesidad de crear sentencias de constitucionalidad, de tutela y unificadas que estructurales o no, en su beneficio.

Existe omisión legislativa, cuando el legislador no cumple deberes de acción señalados expresamente en tratados, convenios y constitución política que al ser interpretados por el juzgador de manera integral para solucionar problemas sociales, generan sentencias integrales. La ausencia de normas y políticas públicas, tiene como efecto provocador la 
jurisprudencia constitucional que avizora mejores escenarios para el reconocimiento de la dignidad humana de comunidades indígenas, como premisa pro homine.

Derechos de autonomía e identidad, la posibilidad de explotar riquezas y recursos mediante consulta, autogobierno y desarrollo sostenible mantienen vigentes prerrogativas jurídicas y aplicación de juicios de igualdad en la jurisprudencia de la Corte Constitucional, implica desentrañar formas integrativas entre principios, valores, normas y contextos, como presupuesto de proporcionalidad entre mandato y prohibición, deber ser normativo y ser del Estado, responsabilidad y realidad social, vulnerabilidad y amenaza frente a protección de derechos humanos.

En consecuencia, la acción de tutela como mecanismo preferente y sumario para la protección de los derechos de los pueblos indígenas, considerados sujetos de especial protección constitucional, por razones históricas y culturales, hacen necesaria una protección inmediata y extensa que se expresa en las muchas sentencias de la Corte Constitucional entre ellas las estructurales, que reconocen derechos étnicos ordenando protección integral mediante normas, política pública y acciones de seguimiento y veeduría a órdenes que integran derecho con principios y valores con realidad social como medidas de compensación.

\section{Referencias bibliográficas}

Beloff, Mary - Clérico, Laura (2016). Derecho a condiciones de existencia digna y situación de vulnerabilidad en la jurisprudencia de la Corte Interamericana. Estudios constitucionales, 14. 139-178.

Corte IDH. "Niños de la calle” (Villagrán Morales y otros.) vs. Guatemala. 19 noviembre 1999.

Corte IDH. Pueblo Saramaka vs. Suriname. 28 noviembre 2007.

Corte IDH. Rosendo Cantú et al. vs. México. 31 agosto 2010.

Corte IDH. Pueblo Indígena Kichwa de Sarayaku vs. Ecuador. 27 junio 2012.

Declaración de las Naciones Unidas sobre pueblos indígenas. 2007.

Decreto 1320 de 1998, Leyes 134 de 1994, 21 de 1991, y 70 de 1993.

Observación (CEACR), adopción 2008, Publicación, 98a , reunión CIT, 2009. Convenio pueblos Indígenas y tribales, 1989, No 169, Ratificación, Colombia 1991.

Observación (CEACR), adopción 2015, Publicación: 105ª , reunión CIT, 2016.

Skliar, Carlos (2008). ¿Incluir las diferencias? Sobre un problema mal planteado y una realidad insoportable. Orientación y Sociedad, 8. 1-18.

Stavenhagen, Rodolfo (1990). Derecho consuetudinario indígena en América Latina. Grandes Temas, 15. 